\title{
IMPROVED GAS CORE PROPULSION MODEL
}

\author{
J. E. Tanner \\ Westinghouse Idaho Nuclear Co. \\ Box 4000, ms 2311, Idaho Falls, ID 83403 \\ $208525-6714$
}

\section{ABSTRACT}

A thermodynamic, radiation transport model of a gas core nuclear propulsion reactor has been developed in one-dimensional, spherical geometry, which satisfies local energy balance and allows for arbitrary variation of fuel/propellant ratio and flow rate as functions of radius. Initial cases calculated yield specific impulses of about $1150 \mathrm{sec}$, but very low thrusts ranging 5-10 kN.

\section{INTRODUCTION}

A one-dimensional calculational model of a gas core nuclear propulsion reactor is presented, and a few initial results. A number of restrictions of previous gas core models are relaxed for greater realism:

1) an arbitrary degree of mixing of fuel and propellant, which can vary with radial location, is provided for,

2) local values of composition, flow rates, enthalpies, opacities, and temperatures, rather than core average values, are used in the neutronics and radiation transport calculations,

Hydrodynamic calculations are not performed, but the effect of an assumed non-turbulent (streamline) mixing of fuel and propellant is modeled. However the effects of arbitrary amounts of turbulence could be included without major changes in the calculations. Since no turbulence is modeled, all heat transport is by radiation. Transport by molecular diffusion would be insignificant.

The questions which can be answered are the effects of mixing, core temperature, flow profile, and choice of fissile isotope on thrust, specific impulse, and fuel loss.

The neutronics and radiation transport calculations were performed in spherical symmetry. This allows a representation of the heating of the gas as it enters from the sides and moves various distances inward before exiting through the throat. It also allows a representation of heat transfer from center to outside, as will happen in an actual engine. In a sense, front- to back-of-the-engine properties are thus averaged over each shell, but that may be the best that can be done in a onedimensional representation of a two-dimensional engine. Calculations in one-dimensional cylindrical symmetry would be no more realistic because again there would be large changes in both radial and axial directions in a real engine.

For numerical calculations the engine cavity was divided into annuli, usually 10 , but in one case 30. The gas is assumed to reach the nozzle from each annulus at rates and compositions arbitrarily assigned for each, and at temperatures that were solved for.

\section{MASTER}

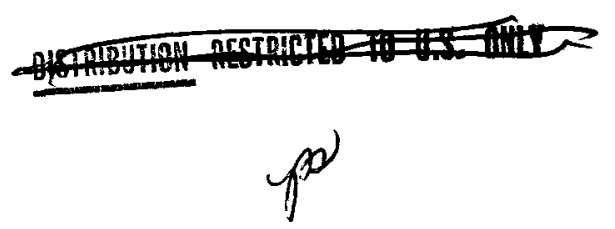




\section{DISCLAIMER}

This report was prepared as an account of work sponsored by an agency of the United States Government. Neither the United States Government nor any agency Thereof, nor any of their employees, makes any warranty, express or implied, or assumes any legal liability or responsibility for the accuracy, completeness, or usefulness of any information, apparatus, product, or process disclosed, or represents that its use would not infringe privately owned rights. Reference herein to any specific commercial product, process, or service by trade name, trademark, manufacturer, or otherwise does not necessarily constitute or imply its endorsement, recommendation, or favoring by the United States Government or any agency thereof. The views and opinions of authors expressed herein do not necessarily state or reflect those of the United States Government or any agency thereof. 


\section{DISCLAIMER}

Portions of this document may be illegible in electronic image products. Images are produced from the best available original document. 


\section{MODEL}

The plasma occupied a spherical cavity of radius $150 \mathrm{~cm}$, and the pressure was fixed at 101.3 $\mathrm{MPa}(1000 \mathrm{~atm})$ for all cases calculated. A $60 \mathrm{~cm} \mathrm{BeO}$ reflector was provided, the inner $40 \mathrm{~cm}$ of which was set at a temperature of $2500 \mathrm{~K}$, and the outer $20 \mathrm{~cm}$, at $1200 \mathrm{~K}$. For all but the first case calculated a $5 \mathrm{~cm}$ inner graphite liner at $3000 \mathrm{~K}$ was provided.

\section{RADLATION TRANSPORT}

Since the plasma is optically dense at all but the lowest temperatures and uranium concentrations, a diffusion approximation of radiation transport may be used. Assuming a refractive index of unity, and ignoring scattering, the basic relation for local energy balance is:

radiant heat outflow $=$ fission heat - heat to warm incoming gas,

$$
-\frac{4}{3} \nabla \cdot \frac{1}{k} \nabla\left(\sigma T^{4}\right)=Q_{f}(r)-Q_{a b s}(r)
$$

In spherical symmetry, and with boundary conditions $\mathrm{dT} / \mathrm{dr}=0$ at $\mathrm{r}=0$, and arbitrary wall temperature, $\mathrm{T}_{1}$, the solution is:

$$
\sigma T^{4}(r)=\sigma T_{1}^{4}+\frac{3}{4} \int_{r}^{r_{1}} \frac{k\left(r^{\prime}\right)}{r^{\prime 2}} \int_{0}^{r^{\prime}} r^{\prime \prime 2}\left(Q_{f}\left(r^{\prime \prime}\right)-Q_{a b s}\left(r^{\prime \prime}\right)\right) d r^{\prime \prime} d r^{\prime}
$$

where $r$ is radial location, $T$ is temperature, $Q_{\mathfrak{f}}$ is the rate of fission energy production, $Q_{a b s}$ is the rate of energy absorption due to warming, and $\mathrm{k}$ is the opacity(Rosseland mean absorption coefficient), all being local quantities; $\sigma$ is the Stefan-Boltzmann constant, and $\nabla$ is the vector differential operator.

For division into spherical annuli the above double integral was converted into a double sum, where $\mathrm{k}, \mathrm{Q}_{\mathrm{abs}}$, and $\mathrm{Q}_{\mathrm{f}}$ were assumed constant within each annulus, but explicit functions of radius were integrated within each annulus. The result is:

$$
\begin{aligned}
\sigma T_{j}^{4}=\sigma T_{o}^{4}+\frac{k_{m}}{4} \sum_{m=j+1}^{n} & {\left[\left\{\frac{\left(k_{m} \Delta_{m}\right)}{\left(r_{m} r_{m-1}\right)}\right\} \sum_{i=1}^{m-1}\left(Q_{f}-Q_{a b s}\right)_{i}\left(r_{i}^{3}-r_{i-1}^{3}\right)\right.} \\
& \left.+\frac{1}{2}\left(r_{m}^{2}-3 r_{m-1}^{2}+2 \frac{r_{m-1}^{3}}{r_{m}}\right)\left(Q_{f}-Q_{a b s}\right)_{m}\right]
\end{aligned}
$$

In this equation $k, Q_{a b s}, Q_{f}$, and $\Delta_{m}=r_{m}-r_{m-1}$ are averages for the respective annuli, while $r$ and $T$ are at their outer boundaries. $\boldsymbol{n}$ is the number or annuli, usually 10 . 


\section{OPACITY}

Measurements and calculations of the opacities of hydrogen ${ }^{1}$ and uranium ${ }^{2}$ plasmas at high temperatures and pressures are available for these two substances separately, but not for their mixtures. Also, the values for uranium do not extend to as low a pressure as was needed here. The simple assumption was made that the opacities are additive over short wavelength intervals. Mean opacities were calculated by integrating the reciprocal of the summed opacities over the important part of the wavelength spectrum, according to the Rosseland ${ }^{3}$ formula. Details of the procedure used have been presented elsewhere. ${ }^{4}$

Admittedly even the assumption of additivity over short wavelength intervals is not entirely accurate, since the presence of each element will influence the degree of ionization of the other, as is discussed later.

It was desired to have opacities of uranium down to partial pressures of $0.101 \mathrm{MPa}$ ( $1 \mathrm{~atm}$ ). The main guidance in the extrapolation from higher pressures was the single value reported by Parks $e t \mathrm{al}^{2}$ at $5000 \mathrm{~K}$ and $36 \mathrm{~Pa}$. Maceda and Miley ${ }^{5}$ calculated opacities at $0.101 \mathrm{MPa}(1 \mathrm{~atm})$ from $5000 \mathrm{~K}$ to $8000 \mathrm{~K}$. Rosseland mean opacities were calculated from their results at $5000 \mathrm{~K}$ and $8000 \mathrm{~K}$, but they were of limited usefulness because they yielded the unlikely result of a lower opacity at $8000 \mathrm{~K}$.

With the above guidance, the extrapolations were done by dividing the specific opacities $\left(\mathrm{cm}^{2} / \mathrm{g}\right)$ reported by Parks et $a l^{2}$ at $10.13 \mathrm{MPa}(100 \mathrm{~atm})$ at each wavelength by 4.5 and 1.6 to give specific opacities at $0.1013 \mathrm{MPa}$ and $1.013 \mathrm{MPa}(1$ and $10 \mathrm{~atm})$, respectively, then converting to volume opacities $\left(\mathrm{cm}^{-1}\right)$, adding hydrogen opacities corresponding to a total pressure of $101.3 \mathrm{MPa}(1000$ $\mathrm{atm})$, and performing the Rosseland integration. This was repeated at each temperature.

Extrapolation of the uranium opacities down to $3000 \mathrm{~K}$ was done by a 3-point Lagrangian formula from the values at $5000 \mathrm{~K}, 6500 \mathrm{~K}$, and $8000 \mathrm{~K}$, using logarithms of the values. A few of the lowest opacities were adjusted smoothly so as to be not less than $5 \mathrm{~cm}^{-1}$. It was assumed that the plasma could be seeded to maintain at least this opacity.

\section{ENTHALPY}

Enthalpies of uranium-hydrogen mixtures were computed by simple addition of the enthalpies of the pure substances at their respective partial pressures, from the values presented in references 2 and 6 . Uranium enthalpies below $10.13 \mathrm{MPa}$ (100atm) were calculated by simple logarithmic extrapolation of the values of Parks et al $l^{2}$ from 10.13 MPa-101.3 MPa (100-1000atm). High accuracy is not important in the extrapolation since uranium makes only a small contribution to total enthalpy much below $10 \mathrm{MPa}$ uranium partial pressure.

The rates of heat absorption, $\mathrm{Q}_{\mathrm{abs}}$, in each region were computed as the heat capacity times radial temperature derivative times flow rate across the annulus, summed over each annulus interior to and including the annulus under consideration. 


\section{FISSION HEAT}

Gamma ray heat transport to the walls was assumed to amount to $6.7 \%$ of the fission energy. Then $\mathrm{Q}_{\mathrm{f}}$ 's were normalized so that the total fission energy for transport of radiation in the nearvisible region equaled $93.3 \%$ of the enthalpy of the gas exiting the nozzle, relative to the same substance near zero K.

\section{DENSITIES}

Plasma densities of uranium-hydrogen mixtures were needed for converting between partial pressures and atom densities, and for converting opacities and enthalpies between per-mass and per-volume units. Pure hydrogen densities have been presented by Patch ${ }^{6}$ over the pressure and temperature range needed. As with the other quantities, the uranium densities presented by Parks et $a l^{2}$ needed to be extrapolated below $10.13 \mathrm{MPa}(100 \mathrm{~atm})$. The best method seemed to be to calculate ionization equilibrium constants from the species concentrations presented there, and use these for density calculations at the lower partial pressures of uranium. This procedure gave remarkably (probably fortuitously) good agreement with the single low pressure density reported at $5000 \mathrm{~K}$ and $36 \mathrm{MPa}^{2}$

The simple procedure of summing densities of uranium and hydrogen at their respective partial pressures undoubtedly leads to lower than actual computed densities, since they have an ionization product in common--electrons. The effect is probably greatest at temperatures above $15000 \mathrm{~K}$, where significant ionization of hydrogen occurs even at higher pressures. No correction for this effect was attempted.

\section{COMPOSITIONS}

The gas exiting each annulus at some time passes through each annulus exterior to it. Exit $\mathrm{H} /$ U's for each annulus are determined as described later. H/U's for the neutronics calculations are calculated by averaging the exit $\mathrm{H} / \mathrm{U}$ 's of each annulus interior to and including the annulus under consideration, weighted by the mass flow rate for that annulus.

\section{NEUTRONICS}

The $\mathrm{MCNP}^{7}$ Monte Carlo code was used for all neutronics calculations. For hydrogen the continuous energy cross section set $\# 1001.50 \mathrm{c}$, based on $\mathrm{ENDF} / \mathrm{B}-\mathrm{V}^{8}$ data was used. Uranium continuous energy cross section sets were prepared at $3000 \mathrm{~K}, 6000 \mathrm{~K}, 10000 \mathrm{~K}, 20000 \mathrm{~K}$, and $50000 \mathrm{~K}$, using the NJOY ${ }^{9}$ code with ENDF/B-V data. For any given annulus the cross section set prepared at the next lower temperature was used.

\section{CALCULATIONAL PROCEDURE}

The calculational procedure is outlined in Fig.1. The radial dependences (constant, linear, etc.) of flow rates, $\mathrm{v}(\mathrm{r})$, and composition, $\mathrm{H} / \mathrm{U}(\mathrm{r})$, are arbitrarily fixed, but with a magnitude parameter 
to be solved for. The temperature range, representing the power level of the reactor, is arbitrarily decided on, but with a detailed radial dependence to be solved for. The radial bounds of the annuli are kept constant throughout.

Fix $\quad \underline{\text { Solve for }}$

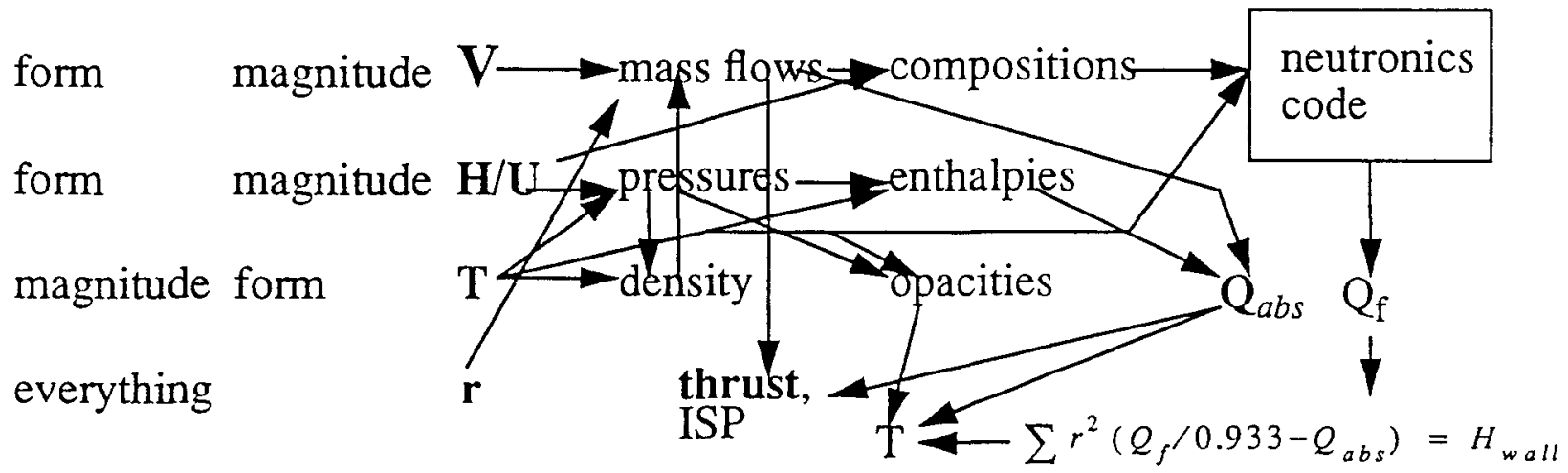

Figure 1. Calculational Flow Chart

Starting with plausible guesses of each of the unknowns, the calculations proceed as far as the compositions, for incorporation of these and the temperatures into the neutronics code. This is repeated with adjustment of the composition magnitude parameter until $k_{\text {eff }}=1 \pm .02$ is achieved. Then, using the calculated relative fission rates the temperatures are calculated. The velocity magnitude parameter is adjusted until the differences between trial and calculated temperatures roughly balance out over the engine. These velocity adjustments do not require repetition of the neutronics calculations because they do not change the calculated $\mathrm{H} / \mathrm{U}$ ratios.

Based on the differences between trial and calculated $T(r)$, two or three more guesses of $T(r)$ are calculated through as outlined above. Thereafter a matrix method is applied to the accumulated trial and resulting $T(\mathrm{r})$ 's to successively calculate improved $\mathrm{T}(\mathrm{r})$ guesses. After 6-8 trials in all, $\mathrm{T}(\mathrm{r})$ will have converged to within $100^{\circ}$ of an eigenvector of $\mathrm{Eq}(3)$ for all of the annuli. This is judged to be sufficient accuracy for calculating the quantities originally desired--thrust and specific impulse (ISP).

Thrust and specific impulse are calculated with what may be an optimistic assumption of complete recombination of atomic hydrogen in the throat and nozzle. Assuming these are ideal, then thrust is the square root of energy production (=absorption) rate times mass exhaust rate; and ISP is the square root of the ratio of these quantities.

\section{RESULTS}

Three cases have been calculated to convergence. The parameters are presented in Table I. In case 3 the atom fraction of uranium declines linearly from 0.05 at the center to zero at the wall. 
Velocities for all cases were set to increase linearly with distance from the center..

Table 1: Parameters for Solved Gas-Core Cases

\begin{tabular}{ccccccccc} 
Case & $\begin{array}{c}\text { Graphite } \\
\text { Liner }\end{array}$ & $\begin{array}{c}\text { Flow, } \\
\mathrm{cm} / \mathrm{s}\end{array}$ & $\begin{array}{c}\text { Individual } \\
\mathrm{H} / \mathrm{U}\end{array}$ & $\begin{array}{c}\text { Exhaust } \\
\mathrm{H} / \mathrm{U}\end{array}$ & $\begin{array}{c}\text { Temper } \\
\text { Center }\end{array}$ & $\begin{array}{c}\text { ature, } \\
\text { Wall }\end{array}$ & $\begin{array}{c}\text { ISP, } \\
\text { sec }\end{array}$ & $\begin{array}{c}\text { Thrust, } \\
\mathrm{kN}\end{array}$ \\
\hline \hline 1 & no & $.0257 \times \boldsymbol{r}$ & 124 & 124 & 20320 & 2500 & 1160 & 8.3 \\
2 & yes & $.0227 \times \boldsymbol{r}$ & 92 & 92 & 21250 & 3000 & 1150 & 7.3 \\
3 & yes & $.0147 \times \boldsymbol{r}$ & $\begin{array}{l}\text { U linear } \\
\text { in } \boldsymbol{r}\end{array}$ & 132 & 22950 & 3000 & 1170 & 4.6
\end{tabular}

The specific impulses calculated here are typical of those calculated by others. Thrusts, however, are much lower. Schnitzler, for example, calculated thrusts from $16.9 \mathrm{kN}$ to $2030 \mathrm{kN}$ for a spherical cavity of the same diameter and reflector thickness, and at the same pressure, though at a center temperature of $90000 \mathrm{~K}$. The present model makes far fewer physical assumptions and simplifications, but the question which are most important for the difference is being investigated.

The slightly higher ISP and thrust for case 1 compared to case 2 is due to the slightly lower temperature in and near the wall. $\mathrm{K}_{\text {eff }}$ is much more sensitive to the temperature here than in the interior of the plasma. The much lower thrust for case 3 is apparently due to the higher opacity, except near the edge, which obstructs heat transfer from the center, and also the longer transport distances, since fissions are more concentrated toward the center.

\section{CONCLUSIONS}

It has been possible to remove many of the simplifying assumptions and restrictions previously used in one-dimensional gas core nuclear propulsion reactor models. Initial calculations indicate attractive specific impulses are possible, but much lower thrust than previously estimated.

\section{ACKNOWLEDGMENTS}

This project was funded by the DOE-ID Laboratory Directed Research and Development program through Westinghouse Idaho Nuclear Co.

\section{REFERENCES}

1. R.W.Patch, Interim Absorption Coefficients and Opacities for Hydrogen Plasma at High Pressure, NASA TM X-1902, October 1969.

2. D.E.Parks, G.Lane, J.C.Stewart, and S.Peyton, Optical Constants of Uranium Plasma, NASA CR-72348, GA-8244, February 2, 1968.

3. M.N.Ozisik, Radiative Transfer, Wiley 1973. See chapter 9.

4. Accepted for presentation at the annual meeting of the American Nuclear Society, San Diego, June 20-24, 1993.

5. E.L.Maceda and G.H.Miley, J.Appl.Phys. 49(8), 4369 (1968).

6. R.W.Patch, Thermodynamic Properties and Theoretical Rocket Performance of Hydrogen to 
$100000 \mathrm{~K}$ and $1.01325 \times 10^{8} \mathrm{~N} / \mathrm{m}^{2}$, NASA SP-3069 (1971)

7. MCNP 4, Monte Carlo Neutron and Photon Transport Code System, RSIC Computer Code Collection, Oak Ridge National Laboratory, CCC-200A/B

8. R.Kinsey, Ed., ENDF/B Summary Documentation, BNL-NCS-17541 (ENDF-201), 3rd ed., Brookhaven National Laboratory (1979).

9. R.E.MacFarlane, "The NJOY Nuclear Data Processing System, Version 91.0."Unpublished document, (February 7, 1991).

10. B. G. SCHNTTZLER, "Gas Core Reactors for Direct Nuclear Propulsion", EGG-NE-9087, EG\&G Idaho Co., June 1990.

\section{DISCLAIMER}

This report was prepared as an account of work sponsored-by an agency of the United States Government. Neither the United States Government nor any agency thereof, nor any of their employees, makes any warranty, express or implied, or assumes any legal liability or responsibility for the accuracy, completeness, or usefulness of any information, apparatus, product, or process disclosed, or represents that its use would not infringe privately owned rights. Reference herein to any specific commercial product, process, or service by trade name, trademark, manufacturer, or otherwise does not necessarily constitute or imply its endorsement, recommendation, or favoring by the United States Government or any agency thereof. The views and opinions of authors expressed herein do not necessarily state or reflect those of the United States Government or any agency thereof. 